\title{
Quality of Life of the Royal Thai Navy College of Nursing's Personnel
}

\section{Suwapak VESAMAVIBOOL}

\author{
The Royal Thai Navy College of Nursing, Department Naval Medical, Bangkok 10600, Thailand
}

(Corresponding author's e-mail: suwapak7@yahoo.com)

Received: 7 May 2017, Revised: 11 January 2018, Accepted: 5 February 2018

\begin{abstract}
This was a descriptive research aiming at investigating the quality of life of the Royal Thai Navy College of Nursing's (RTNCN) personnel. There were 325 samples which were from the executives, nursing instructors, supporting staff and nursing students in the academic year 2014. The research tool was the World Health Organization Quality of Life assessment (WHOQOL - BRIEF - THAI) and the reliability of which was tested using the Cronbach's Alpha with the result at 0.91 . The statistics applied in this study were descriptive statistic. The results were as follows: 1) The Quality of Life in the aspects of physical health, psychological state, environment and overview of Quality of Life were mainly at moderate level (66.77, 54.77, 45.54, 75.38 and 57.85 percent respectively); and 2) Analyzing the Mean, it was found that QOL in all aspects of the personnel was at moderate level.
\end{abstract}

Keywords: Quality of life, Royal Thai Navy

\section{Introduction}

Since the $8^{\text {th }}$ National Economic and Social Development Plan, the focus has shifted to the "Humancentered Development" with economy as the tool to improve the quality of life [1]. This is based on the belief that once the people in the community have a good quality of life, they will be equipped with the ability to improve and maximize their own potential, the society and the environment they live in. Hence, the social problems will be gradually diminished.

The World Health Organization (WHO) defines quality of life as a multidimensional perception of an individual toward their position in life in the context of the culture and value systems in which they live and in relation to their goals, expectations, standards, and concerns. It is a broad ranging concept affected in a complex way by the person's physical health, psychological state, level of independence, social relationships, personal beliefs and their relationship to salient features of their environment. [2]

The Royal Thai Navy College of Nursing (RTNCN), Naval Medical Department has direct responsibility to produce nursing graduates excelling in providing health services to the military personnel, their families and other civilians in peacetime, emergency situations and wartime. The college's personnel can be classified into 4 groups: 1) executives, 2) nursing instructors, 3) supporting staff and 4) nursing students. The researcher was interested in studying the level of quality of life of these personnel for further making a human resource development plan to ensure them a better quality of life. According to the World Health Organization, there are 4 elements of quality of life (QOL): 1) physical health perception of oneself in performing daily routines, 2) psychological state perception of oneself, 3) perception on social relationships with others and 4) perception on environment affecting their life. The QOL assessment is subjective and embedded in the individual's cultural, social and environmental context [3]. This development is in accordance with the Royal Thai Navy Commander-in-Chief's policy in Fiscal Year 2015 in promoting and providing better welfares and services to the Royal Thai Navy's personnel and their families to boost up their morale and guarantee them a better quality of life which will result in better work quality and loyalty to the organization.

Walailak J Sci \& Tech 2019; 16(1): 39-45. 


\section{Materials and methods}

The population of the study were 325 RTNCN's personnel, consist of the following: 1) 17 executives, who are responsible for directing and supervising all the personnel to achieve the organization's goals, 2) 24 nursing instructors who are responsible for the tasks of teachers in higher education institutions, such as teaching and learning management, research, and provide academic services emphasizing continuous life-long learning for society and Art and Culture Conservation, 3) 25 supporting staff, responsible for providing a variety of administrative support functions, official documents and academic documents, and 4) 259 nursing students in academic year 2014.

The World Health Organization Quality of Life assessment (WHOQOL - BRIEF - THAI) was used to explore QOL of population which was developed by Mahatnirunkul et al. [3]. WHOQOL - BRIEF THAI consisted of 26 items and 2 question types: Perceived objective and Self-report subjective. It assessed the overview of QOL (2 items) and each of the 4 elements of QOL which were 1) physical aspect (7 items), 2) psychological state aspect (6 items), 3) social relationship (3 items) and 4) environmental aspect (8 items).

The QOL scores are divided into 3 levels: good (96 - 130 scores), moderate (61 - 95 scores) and poor (26 - 60 scores).

\begin{tabular}{cccc}
\hline Aspects & Poor & Moderate & Good \\
\hline Physical health & $7-16$ & $17-26$ & $27-35$ \\
Psychological state & $6-14$ & $15-22$ & $23-30$ \\
Social relationships & $3-7$ & $8-11$ & $12-15$ \\
Environmental & $8-18$ & $19-29$ & $12-15$ \\
overview of QOL & $26-60$ & $61-95$ & $96-130$ \\
\hline
\end{tabular}

The instrument's reliability was tested by piloting it with 30 personnel at the Naval Operational Medicine School, Naval Medical Department. The result was then calculated using Cronbach's alpha coefficient and it showed that the reliability of the instrument was at 0.91 . Descriptive statistics including number and percentage were used to analyze demographic factors which were age, educational level, marital status, monthly income, working level, and QOL level.

\section{Results and discussion}

For the Characteristics of the population, the majority of the respondents were the fourth year nursing students which constituted 24.62 percent of the population while the smallest group was the executives, 5.23 percent. Almost all of the populations were female holding 96.62 percent. The average age was at 25 years old (25.07). The average ages of the executives, the nursing instructors, the supporting staff, and the nursing students were at 50.06, 39, 43.88 and 20.34 years old respectively. In terms of educational qualification, 86.46 percent were at a level lower than bachelor's degree, 7.39 percent graduated with master's degree, 4.00 percent with bachelor's degree, and 2.15 percent with doctorate' degree. Most of them were single making up 86.46 percent of the whole population while 10.77 percent were married. Majority of them, 68.62 percent, earned lower than 5,000 baht per month whereas the next ranking group, 13.23 percent, earned approximately 5,000 - 10,000 baht a month.

The QOL Level of the personnel at the Royal Thai Navy College of Nursing, QOL in the aspects of physical health, psychological state, environment and overview of QOL was mainly at the moderate level at $66.77,54.77,75.38$, and 57.85 percent respectively. In terms of social relationship, the results were generally at good level constituting 52.61 percent, and the mean scores and SD of QOL of the RTNCN's personnel were consistent at moderate level (Table 1). 
http://wjst.wu.ac.th

Table 1 QOL Level of the personnel at the Royal Thai Navy College of Nursing.

\begin{tabular}{|c|c|c|c|c|c|c|c|c|c|}
\hline \multirow{3}{*}{ Aspects } & \multicolumn{9}{|c|}{ Quality of Life Level } \\
\hline & \multicolumn{2}{|c|}{ Poor } & \multicolumn{2}{|c|}{ Moderate } & \multicolumn{2}{|c|}{ Good } & \multirow{2}{*}{ mean } & \multirow{2}{*}{ SD } & \multirow{2}{*}{ Level } \\
\hline & $\mathbf{N}$ & $\%$ & $\mathbf{N}$ & $\%$ & $\mathbf{N}$ & $\%$ & & & \\
\hline Physical health & 4 & 1.23 & 217 & 66.77 & 104 & 32.00 & 24.92 & 3.24 & Moderate \\
\hline Psychological state & 3 & .92 & 178 & 54.77 & 144 & 44.31 & 21.86 & 3.07 & Moderate \\
\hline Social relationship & 6 & 1.85 & 148 & 45.54 & 171 & 52.61 & 11.48 & 1.77 & Moderate \\
\hline Environment & 9 & 2.77 & 245 & 75.38 & 71 & 21.85 & 26.42 & 4.18 & Moderate \\
\hline Overview of QOL & 3 & .92 & 188 & 57.85 & 134 & 41.23 & 91.60 & 11.13 & Moderate \\
\hline
\end{tabular}

Analyzing the Mean, it was found that QOL in all aspects of the personnel was at moderate level. The items received the highest mean scores were No 23 To what extent do you feel your life to be meaningful? (Mean $=4.24, \mathrm{SD}=0.74)$, No 11 How much do you not need any medical treatment to function in your daily life? (Mean $=4.14, \mathrm{SD}=0.80$ ), and No 24 How well are you able to get around? $($ Mean $=4.04, \mathrm{SD}=0.79)$. Those had lowest mean scores were No 4 How satisfied are you with your sleep? $($ Mean $=2.61$, SD = 1.04), No 20 To what extent do you have the opportunity for leisure activities? $($ Mean $=2.64, \mathrm{SD}=0.79)$ and No 19 How available to you is the information that you need in your dayto-day life? $($ Mean $=2.82, \mathrm{SD}=0.85)($ Table 2).

Table 2 The Mean QOL Scores of the Royal Thai Navy College of Nursing's Personnel.

\begin{tabular}{|c|c|c|c|}
\hline Item & In the last two weeks & Mean & SD \\
\hline 1 & How satisfied are you with your health? & 3.31 & 0.76 \\
\hline 2 & To what extent do you feel that physical pain not prevent you from doing what you need to do? & 3.29 & 0.87 \\
\hline 3 & Do you have enough energy for everyday life? & 3.62 & 0.73 \\
\hline 4 & How satisfied are you with your sleep? & 2.61 & 1.04 \\
\hline 5 & How much do you enjoy life? & 3.29 & 0.78 \\
\hline 6 & How well are you able to concentrate? & 3.31 & 0.68 \\
\hline 7 & How satisfied are you with yourself? & 3.70 & 0.70 \\
\hline 8 & Are you able to accept your bodily appearance? & 3.76 & 0.72 \\
\hline 9 & How often do you not have negative feelings such as blue mood, despair, anxiety, depression? & 3.56 & 0.75 \\
\hline 10 & How satisfied are you with your ability to perform your daily living activities? & 3.68 & 0.71 \\
\hline 11 & How much do you not need any medical treatment to function in your daily life? & 4.14 & 0.80 \\
\hline 12 & How satisfied are you with your capacity for work? & 3.54 & 0.71 \\
\hline 13 & How satisfied are you with your personal relationship? & 3.84 & 0.72 \\
\hline 14 & How satisfied are you with the support you get from your friends? & 3.96 & 0.72 \\
\hline 15 & How safe do you feel in your daily life? & 3.82 & 0.75 \\
\hline 16 & How satisfied are you with the conditions of your living place? & 3.59 & 0.91 \\
\hline 17 & Have you enough money to meet your needs? & 3.57 & 0.82 \\
\hline 18 & How satisfied are you with your access to health services? & 3.54 & 0.84 \\
\hline 19 & How available to you is the information that you need in your day-to-day life? & 2.82 & 0.85 \\
\hline 20 & To what extent do you have the opportunity for leisure activities? & 2.64 & 0.79 \\
\hline 21 & How healthy is your physical environment? & 3.16 & 0.76 \\
\hline 22 & How satisfied are you with your transport? & 3.28 & 0.86 \\
\hline 23 & To what extent do you feel your life to be meaningful? & 4.24 & 0.74 \\
\hline 24 & How well are you able to get around? & 4.04 & 0.79 \\
\hline 25 & $\begin{array}{l}\text { How satisfied are you with your sex life? } \\
\text { (sex life refers to the relaxation method that persons use when they have a sexual desire such as } \\
\text { sexual activity, masturbation or sexual intercourse.) }\end{array}$ & 3.68 & 0.88 \\
\hline 26 & How would you rate your quality of life? & 3.60 & 0.73 \\
\hline
\end{tabular}


http://wjst.wu.ac.th

The majority of RTNCN's Personnel had the QOL score in the moderate level, except the executive group which had good QOL score in physical health aspect (mean $=27.35 \mathrm{SD}=2.81$ ), psychological state aspect $($ mean $=23.41 \mathrm{SD}=3.61)$ and Overview of QOL $($ mean $=99.53 \mathrm{SD}=11.85)$. In addition, the executive group had mean scores higher than other groups in every aspect.

The nursing instructors had QOL scores in physical health aspect (mean $=25.67 \mathrm{SD}=3.77$ ) and psychological state aspect (mean $=22.42 \mathrm{SD}=3.22$ ) lower than the supporting staff.

The nursing students had the lowest QOL scores in every aspect except the social relationship aspect which was higher than the nursing instructors and supporting staff (mean $=11.55 \mathrm{SD}=1.67$ ).

The supporting staff had the lowest QOL scores in social relationship aspect $($ mean $=10.68 \mathrm{SD}=$ 2.50) (Table 3).

Table 3 Average, standard deviation and quality of life classified by RTNCN personnel duties.

\begin{tabular}{|c|c|c|c|c|c|c|c|c|c|c|c|c|}
\hline \multirow{2}{*}{ Aspects } & \multicolumn{2}{|c|}{ Executives } & \multirow{2}{*}{ Level } & \multicolumn{2}{|c|}{$\begin{array}{c}\text { Nursing } \\
\text { instructors }\end{array}$} & \multirow{2}{*}{ Level } & \multicolumn{2}{|c|}{$\begin{array}{c}\text { Supporting } \\
\text { staffs }\end{array}$} & \multirow{2}{*}{ Level } & \multicolumn{2}{|c|}{$\begin{array}{l}\text { Nursing } \\
\text { students }\end{array}$} & \multirow{2}{*}{ Level } \\
\hline & Mean & SD & & Mean & SD & & Mean & SD & & Mean & SD & \\
\hline Physical health & 27.35 & 2.81 & Good & 25.67 & 3.77 & Moderate & 26.16 & 3.97 & Moderate & 24.57 & 3.64 & Moderate \\
\hline Psychological state & 23.41 & 3.61 & Good & 22.42 & 3.22 & Moderate & 22.88 & 4.07 & Moderate & 21.61 & 2.87 & Moderate \\
\hline Social relationship & 11.76 & 1.68 & Moderate & 11.29 & 1.88 & Moderate & 10.68 & 2.50 & Moderate & 11.55 & 1.67 & Moderate \\
\hline Environment & 29.76 & 3.87 & Moderate & 27.38 & 5.36 & Moderate & 26.36 & 5.15 & Moderate & 26.12 & 3.88 & Moderate \\
\hline Overview of QOL & 99.53 & 11.85 & Good & 93.42 & 13.72 & Moderate & 93.16 & 14.81 & Moderate & 90.76 & 10.21 & Moderate \\
\hline
\end{tabular}

\section{Discussion}

Study of the QOL level of the personnel at the Royal Thai Navy College of Nursing

From the results, it showed that the QOL mean scores of the personnel at the RTNCN in every aspect were at moderate level which coincided with the results from the survey conducted at Chulalongkorn University. The survey investigated the QOL of the university's personnel by using the 26- item-WHO-BRIEF-THAI assessment form and found that the samples also had moderate level of QOL [4]. The results of the survey also reflected the highest mean score was on the item stating that "the personnel felt life has meaning" while the second rankings were "no need to receive medical treatment to be able to function in daily life" and "able to move around by oneself."

The reason why the personnel at the RTNCN felt that their lives had meaning might derive from the fact that they are part of the college which is the institution producing professional nurses for the society. Most of them are professional nurses who in their working routines have to utilize their skills and knowledge to provide nursing services to suffering patients to be able to recover and live a happy life. The executives and nursing instructors involve directly in delivering theoretical and clinical instructions while the nursing students practice and apply the skills and knowledge to help the patients. This will make them feel they live a meaningful life as their ability can fulfill their esteem needs, to be respected and accepted. According to Maslow, the esteem needs are the individual's desire to be perceived as a valuable person, and the needs can be achieved by utilizing one's ability to prove oneself. Once the needs are fulfilled, the self-confidence will develop as the individual will realize their own value and feel needed [5]. The working nature might also contribute to the personnel's feeling that their life has meaning as shown in the results of the study conducted by Choeisuwan et al. [6]. The results of the study investigating the factors affecting the retention of nursing instructors at the RTNCN showed that the instructors felt that their work helped build up the overall success of the organization and it was the factor receiving the highest mean score in the study. Furthermore, Yaemsuda et al. [7] investigated the factors contributing to well-being and satisfaction of the personnel at the Naval Medical Department. From the 
study, the personnel mostly rated the life satisfaction as the reflection of happiness in life and the pride to be part of the organization's success reflected the happiness in work. It could be concluded that the nursing instructors felt that they were useful and valuable to the organization and other people.

The supporting reason why the personnel felt that there was no need to receive any medical treatment to function in daily life and they were able to move around by themselves might be the age of the personnel. The demographic information showed that the age of the college personnel ranged from 17 to 60 with the average age at 25.07 years old (SD 10.43). The majority was in late adolescence (79 persons) with full physical development, and most theories stated that it was the age of becoming independent, moving away from the state that they depended on others.

The items receiving the lowest mean scores were dissatisfaction about sleeping and opportunity to relax. This might be resulted from the fact that most of the samples were nursing students (79.69 percent) whose daily life was similar to those studying in other military academies. They stayed in dormitory during working days and went back home on weekends if they were not on duty. They shared the accommodation with other students, 8 - 10 students in one room; hence, they did not have much privacy, freedom and time to do individual recreational activity. Moreover, the second and third year students needed to take turn to have practical experience in wards and they were divided into 3 shifts, in the morning, in the afternoon and at night. The different working hours and sharing the same living quarters would definitely affect the sleeping condition of the students. Moreover, the night shift starting from $00.00-08.00$ and resting at $08.00-16.00$ would disturb the sleeping pattern and affect the sleeping quality of the students. This should be the reason why the samples stated that they were not satisfied with the sleeping condition. Investigating closely, there were 50 persons from 325 samples considering 15.38 percent who stated that they were totally not satisfied with the sleeping condition. Apparently, it is the issue that is needed to be addressed immediately as the quality of sleep has the direct effect on physical and mental health. According to the result of this research, the nursing student group had QOL mean scores in physical health aspect, psychological state aspect and environmental aspect lower than all group.

The executive group had mean scores higher than other groups in every aspect, the physical health, psychological state aspects and overview of QOL were in a good level (76.47, 70.59 percent respectively) while other groups had QOL score in a moderate level only (16.67-56 percent). Since the executive group were in the middle aged (mean 50.05 years old), they were also consistent with the highest average of good physical health according to the questions "How well are you able to get around?" (mean $=4.18 \mathrm{SD}$ $=0.53$ ) "Do you have enough energy for everyday life?" (mean $=4.06 \mathrm{SD}=0.43)$ This showed that the executive group had a good physical health.

According to Erikson's psychosocial theory of development, when people reach middle-aged stage, it involves finding meaning in life and contributing to the development of others such as, mentoring, sharing, caring, generosity and creative advice. Caring helps achieve satisfaction and improve selfesteem. The role of the executive group was reflected from Erikson's theory. In order to achieve organization's goals, they had to teach, share the knowledge and experience to their subordinates and in return they will have a satisfied and meaningful life [8]. As a result, they had a good level in psychological state aspect which was also found out from the question "To what extent do you feel your life to be meaningful?" (mean $=4.29 \mathrm{SD}=0.59$ ).

The nursing instructor group had QOL scores in physical health aspect (mean $=25.67 \mathrm{SD}=3.77$ ) and psychological state aspect (mean $=22.42 \mathrm{SD}=3.22$ ) lower than the executive group and the supporting staff group. Because the nursing instructors were the key person to manage teaching and learning processes, research, and provide academic services emphasizing continuous life-long learning for society and Art and Culture Conservation and responsible for supporting the organization's mission as a whole. Nursing instructors had heavy workload more than other groups. Since 2008, the number of nursing students had been increasing while nursing instructors were likely to decrease [6]. The remaining nursing instructors had excessive workload fatigue, stress and finally effect the physical health. 
http://wjst.wu.ac.th

\section{Conclusions}

This study concluded that among the 4 groups of respondents, the nursing students have the least percentage of QOL as a whole which was determined by WHOQOL-BRIEF-THAI assessment tool. The physical health, psychological state, social relationship, environment and the overview of the QOL have a significant effect on the QOL of the nursing students, nursing instructors and supporting staff which were at moderate level. On the other hand, it is evident that the QOL aspects are at a better level with the executive group.

The quality of life is an important aspect because it embodies the overall well-being, happiness, as well as good physical and emotional health. Therefore, further studies are recommended to improve and maintain the QOL of the nursing students as well as other personnel of the Royal Thai Navy College of Nursing.

\section{Recommendations}

The result showed that the QOL mean score of the personnel and the nursing students was at moderate level which means the college's executives should have a clear policy in developing the personnel's quality of life. There should be clear responsible sectors assigned to deal with every aspect of QOL development. The priority of the problematic areas to be dealt with should be as follows;

1) Lack of quality sleep in nursing students. The instructional system, conduct of activities, and living patterns in dormitory need to be revised to be able to set an appropriate plan to tackle the problem.

2) Opportunity to relax. This is a 2-way problem as poor quality sleep leads to stress and vice versa. Therefore, there should be time allocated or other means to allow the students to have their own way of relaxation.

3) Being able to receive necessary information in daily life. This will assist the personnel to be able to catch up with the current issues and changes in the environment and the world. As a result, there should be a setup of facilities that will assist the personnel and the nursing students to continuously and consistently gain access to the news and information.

4) Conducting a workload analysis of nursing instructors for balancing the work and personal life.

5) The RTNCN should provide recreational activities such as doing exercise every Wednesday afternoon which followed the health promotion policy of the Royal Thai Navy.

\section{Acknowledgements}

The Researcher would like to thank The Royal Thai Navy College of Nursing for funding this research.

\section{References}

[1] National Economic and Social Development Board Office of the Prime Minister. The Eleventh National Economic and Social Development Plan (2012 - 2016), Available at: http://www.nesdb.go.th/nesdb_en/ewt_dl_link.php?nid=3786, accessed January 2014.

[2] The WHOQOL Group. The World Health Organization Quality of Life Assessment (WHOQOL): Development and general psychometric properties. Soc. Sci. Med. 1998; 46, 1569-85.

[3] S Mahatnirunkul, W Tuntipivatanakul and W Pumpisanchai. Comparison of the WHOQOL-100 and the WHOQOL-BREF (26 items). J. Ment. Health Thai 1998; 5, 4-15.

[4] V Chinvechkijvanich, N Huannaklang and O Songrum. The Quality of Life of Chulalongkorn University Survey Project, Available at: http://www.surveillance.cphs.chula.ac.th/attachments/ article/121/Quality of life 2551.pdf, accessed January 2014.

[5] S Serirat, S Hirunkitti, S Suwannapirom, C Prapawanon and S Vanichayaporn. Organization and Management. Thammasan, Bangkok, 2002. 
http://wjst.wu.ac.th

[6] V Choeisuwan, R Changsila, R Sujijantorarat and W Boonrod. Factors related to retention of nursing educators, The Royal Thai Navy College of Nursing. J. Royal Thai Army Nurs. 2013; 14, 51-60.

[7] T Yaemsuda, K Sathuwong, S Siriwong and W Lumwanna. Happiness and satisfaction of Naval Medical's personnel. Royal Thai Air Force Med. Gaz. 1996; 59, 14-21.

[8] SK Kangawan. Personality Psychology Theory. $4^{\text {th }}$ ed. Ruenkaew Printing, Bangkok, 2006. 